\title{
Diet quality of young people in southern Spain evaluated by a Mediterranean adaptation of the Diet Quality Index-International (DQI-I)
}

\author{
M. Mariscal-Arcas ${ }^{1}$, D. Romaguera ${ }^{2}$, A. Rivas ${ }^{1}$, B. Feriche ${ }^{3}$, A. Pons ${ }^{2}$, J. A. Tur ${ }^{2}$ and F. Olea-Serrano ${ }^{1 *}$ \\ ${ }^{1}$ Department of Nutrition and Food Science, University of Granada, Campus de Cartuja s/n, 18071 Granada, Spain \\ ${ }^{2}$ Laboratory of Physical Activity Sciences, University of the Balearic Islands, and Research Group on Community Nutrition \\ and Oxidative Stress, Health Sciences Research Institute (IUNICS), E-07122 Palma de Mallorca, Spain \\ ${ }^{3}$ Department of Physical Education and Sports, University of Granada, Campus de Cartuja s/n, 18071 Granada, Spain
}

(Received 13 November 2006 - Revised 25 April 2007 - Accepted 27 April 2007)

The aim of this study was to assess whether the recently developed Diet Quality Index-International (DQI-I) was useful to evaluate the diet quality of a young Mediterranean population. A cross-sectional nutritional survey was carried out in southern Spain (Granada-Andalucia) from 2002 to 2005. Dietary information ( $24 \mathrm{~h}$ recall and FFQ) and socio-demographic and lifestyle data were collected from a representative sample of the population ( $n$ 288, 44.1\% females and 55.9\% males) aged 6-18 years (mean 12.88 (SD 2.78) years). DQI-I was designed according to the method of Kim et al. modified by Tur et al. for Mediterranean populations. It focused on four main characteristics of a high-quality diet (variety, adequacy, moderation and overall balance). This young population from southern Spain obtained $56.31 \%$ of the total DQI-I score, indicating a poor-quality diet. A higher score was associated with a longer breakfast and greater physical activity. The DQI-I may require further modification for application in Mediterranean populations, differentiating between olive oil and saturated fats, among other changes. Further research is needed to develop a new diet quality index adapted to the Mediterranean diet.

Diet quality: Diet Quality Index-International (DQI-I): Young people's diet: southern Spain

The traditional diet in southern Spain corresponds to the typical Mediterranean dietary pattern $(\mathrm{MDP})^{1,2}$. The MDP is characterized by: a high intake of vegetables, legumes, fruits and nuts, cereals (largely unrefined in the past); a high intake of olive oil but a low intake of saturated lipids; a moderately high intake of fish (depending on the proximity to the sea); a low-to-moderate intake of dairy products (mostly cheese or yoghurt); a low intake of meat and poultry; and a regular but moderate intake of wine, generally during meals ${ }^{3-7}$. The MDP has been associated with better health and a longer life ${ }^{3-5,8-11}$ and has been promoted as a model for healthy eating ${ }^{5,8,9,12,13}$. However, there is wide epidemiological evidence of a rapid change in dietary patterns in Mediterranean countries, with a higher consumption of animal products and SFA to the detriment of vegetable foodstuffs ${ }^{4,14-16}$. This trend can be attributed to substantial socio-economic changes throughout Europe over the past 40 years. Departure from the MDP might be accompanied by loss of its protective effects on health, leading to a rise in diet-related diseases such as CVD and cancer ${ }^{7,11,17,18}$.

A nutritional study in the Balearic Islands ${ }^{19-22}$ examined secular changes in dietary patterns in relation to the traditional Mediterranean diet and evaluated compliance of the current diet with nutritional recommendations. In comparison with the prevalent dietary pattern at the beginning of the twentieth century, there was a higher fat and saturated fat content and a lower consumption of fruit and vegetables, reflecting loss of the MDP in the Balearic Islands ${ }^{19}$. By 2004, the mean percentage of adherence to the MDP in this population was $43.14 \%$, which was similar in all socio-demographic and lifestyle groups but with some differences in relation to age, sex and physical status. Thus, young people and the sedentary showed a lower adherence to the $\mathrm{MDP}^{20}$. Similar results were reported by other studies of dietary changes in Mediterranean countries and among their younger inhabitants $4,14-16,23,24$. The finding that MDP was independent of socio-economic level was also reported in a study of Spanish adults ${ }^{2}$.

The objectives of the present study were to assess the diet quality of young people in Granada Province (southern Spain) by means of the Diet Quality Index-International $(\mathrm{DQI}-\mathrm{I})^{25,26}$ and to relate socio-economic factors, habits and body composition to the index scores obtained. Diet quality indexes measure the overall diet quality based on food group consumption, intake of nutrients related to chronic disease and variety of the $\operatorname{diet}^{27-32}$.

\section{Subjects and methods}

This population-based cross-sectional nutritional survey included 288 young individuals aged from 6 to 18 years old from Granada province (southern Spain). They were recruited between 2002 and 2005 from among young federated 
practising skiers at the High-Performance Centre, CAR-Sierra Nevada $(n 88)$ or from among students at schools in the city of Granada ( $n$ 200). Age of 6-18 years was an inclusion criterion. Informed written consent was obtained from parents or tutors of under 18-year-olds and from 18-year-old participants, and the study was approved by the Ethics Committee of the University of Granada.

\section{Questionnaires}

Participants were administered with three questionnaires: questionnaire on socio-economic status, education level, lifestyle factors and health status; $24 \mathrm{~h}$ diet recall; and a validated quantitative $\mathrm{FFQ}^{33-35}$. The FFQ included ninety-seven food items classified by food group (i.e. nine dairy, seven cereals, three eggs, one pulse, twelve meat, five fish, five fats/oils, ten vegetables, twelve fruit, twelve desserts, three sweets/snacks, ten drinks/infusions, three nuts, five various). Data were gathered on the consumption or not of the item, the number of times it was consumed per week, and the amount consumed each time (in household measures). The $24 \mathrm{~h}$ recall studies were performed between February and May. FFQ were administered at the CAR or school or in the young person's home by a trained dietitian between Tuesday and Friday. The Novartis-Dietsource version 1.2 program was used to convert foods into nutrients ${ }^{36}$.

\section{Construction of modified Diet Quality Index-International}

The DQI-I was modified to assess the Andalusia diet, following the Tur et $a .^{26}$ modification of the method developed by Kim et al. ${ }^{25}$. Notably, whereas Kim et al. ${ }^{25}$ established a fat intake that was $\leq 20 \%$ of total energy, Tur et al. ${ }^{26}$ proposed a higher level $(\leq 30 \%)$ for the consumption of fats in the Mediterranean region. The present version of the index also included use of Spanish recommended daily intakes ${ }^{37}$ and a change in the criterion for classifying 'empty-calorie foods'. The DQI-I focuses on four aspects of a high-quality diet (variety, adequacy, moderation and overall balance). Specific diet components are assessed under each category. These categories help users to identify aspects of their diet that may need improvement. The score for each category is the sum of the scores for each component in that category. The total DQI-I score (range $0-100$ points) is the sum of the scores for the four categories (see Table 1).

Variety. Variety was evaluated both as overall variety and as variety of protein sources. The maximum overall variety score was achieved by intake of at least one serving per day from each of the five food groups (meat/poultry/fish/egg, dairy/beans, grains, fruit, and vegetables). The score for the variety of protein sources (meat, poultry, fish, dairy, beans and eggs) was based on intakes of more than half the serving size per day, using data gathered by the FFQ. Portions were based on portion-weight tables for each food group and household measures ${ }^{38}$. The scoring system is described in Table 2.

Adequacy. This category evaluates the adequacy of intake of those dietary elements that are required to protect against under-nutrition and deficiency disorders. The adequacy of fruit, vegetables, grain and fibre intake is dependent on the energy intake. Thus, for energy intakes of $7118 \mathrm{~kJ}$ $(1700 \mathrm{kcal}), 9211 \mathrm{~kJ}(2200 \mathrm{kcal})$ or $11304 \mathrm{~kJ}(2700 \mathrm{kcal})$, the maximum score is assigned to a diet containing two,
Table 1. Diet Quality Index-International (DQI-I) scores and components

\begin{tabular}{llrl}
\hline Component & Score ranges (points) & Mean & SD \\
\hline DQI-I, total & $0-100$ & $56 \cdot 31$ & 9.48 \\
Variety & $0-20$ & $18 \cdot 18$ & $2 \cdot 86$ \\
Overall food group variety & $0-15$ & 13.72 & $2 \cdot 36$ \\
Within-group variety for & $0-5$ & 4.46 & 0.95 \\
protein sources & & & \\
Adequacy & $0-40$ & 26.36 & 4.40 \\
Vegetable group & $0-5$ & 3.76 & 1.49 \\
Fruit group & $0-5$ & 3.52 & 1.64 \\
Grain group & $0-5$ & 2.09 & 1.17 \\
Fibre & $0-5$ & 1.91 & 1.03 \\
Protein & $0-5$ & 4.87 & 0.48 \\
Iron & $0-5$ & 3.36 & 1.29 \\
Calcium & $0-5$ & 3.15 & 1.38 \\
Vitamin C & $0-5$ & 3.62 & 1.62 \\
Moderation & $0-30$ & 10.07 & 6.12 \\
Total fat & $0-6$ & 0.83 & 1.82 \\
Saturated fat & $0-6$ & 0.71 & 1.54 \\
Cholesterol & $0-6$ & 3.38 & 2.77 \\
Sodium & $0-6$ & 4.43 & 2.15 \\
'Empty calorie foods' & $0-6$ & 0.82 & 1.66 \\
Overall balance & $0-10$ & 1.53 & 2.03 \\
Macronutrient ratio & $0-6$ & 0.44 & 1.31 \\
Fatty acid ratio & $0-4$ & 1.08 & 1.58 \\
\hline
\end{tabular}

three or four portions of fruit and three, four or five portions of vegetables, respectively. Likewise, the highest score for grain and fibre categories was assigned to daily intakes of $\geq 6, \geq 9$ and $\geq 11$ portions of grain and $\geq 20, \geq 25$ and $\geq 30 \mathrm{~g}$ fibre for the three energy intake levels, respectively. Protein intake was considered adequate when the proportion of total energy from protein was $>10 \%$. Intakes defining the highest score for adequacy of iron, calcium and vitamin $\mathrm{C}$ were derived from the recommended daily intakes for Spanish people ${ }^{37}$, which vary according to age and gender.

Moderation. This category evaluates the intake of food and nutrients related to chronic diseases, which may need restriction. To emphasize the importance of moderation in fat intake, total fat intake in the DQI-I is evaluated using more stringent cut-off values than those found in other dietary indexes. In our modification of the DQI-I, a score of 6 points was assigned when total fat was $\leq 30 \%$ of total energy/d, 3 points when $30-35 \%$ of total energy/d and 0 points when $>35 \%$ of total energy/d ${ }^{26}$ (Table 2). The intake of saturated fats was also evaluated as the percentage of energy from saturated fat. Intake levels of cholesterol and sodium were also recorded (Table 2). The 'empty-calorie food' component assesses how much a person's energy supply is dependent on low-nutrient density foods, which provide energy alone and supply scant nutrients. The DQI-I states that table sugar, alcohol, oil and similar are empty calorie foods (if the sum of nutrient densities considered across nutrients in a food is $<1$, the food is considered an empty-calorie food). However, some of the foods classified as empty-calorie by Kim et $\mathrm{al}^{25}$ have nutritional value in the MDP and corresponding modifications were therefore made to the DQI-I. Thus, the following were only categorized in the MPD food pyramid as empty-calorie foods if their use was only 'occasional and moderate ${ }^{38}$ : cold meats, pâté, butter, vegetable margarine, bacon, sugar, industrial pastries, sweets, 
Table 2. Components of the Diet Quality Index (DQI-I) and percentage of sample in component subcategories

\begin{tabular}{|c|c|c|c|c|}
\hline \multirow[b]{2}{*}{ Component } & \multirow[b]{2}{*}{ Full score } & \multicolumn{2}{|r|}{ Scoring criteria } & \multirow[b]{2}{*}{$\%$} \\
\hline & & Point & Criteria & \\
\hline Variety & $0-20$ & & & \\
\hline \multirow{6}{*}{ Overall food group variety } & $0-15$ & 15 & $\geq 1$ serving from each food group/d & $70 \cdot 7$ \\
\hline & & 12 & Any 1 food group missing/d & $16 \cdot 6$ \\
\hline & & 9 & Any 2 food groups missing/d & 8.6 \\
\hline & & 6 & Any 3 food groups missing/d & 3.8 \\
\hline & & 3 & $\geq 4$ food groups missing $/ \mathrm{d}$ & 0.4 \\
\hline & & 0 & None from any food group & 0.0 \\
\hline \multirow[t]{4}{*}{ Within-group variety from protein source } & $0-5$ & 5 & $\geq 3$ different sources $/ \mathrm{d}$ & $72 \cdot 2$ \\
\hline & & 3 & 2 different sources/d & $26 \cdot 3$ \\
\hline & & 1 & From 1 source/d & 1.5 \\
\hline & & 0 & None & 0.0 \\
\hline Adequacy & $0-40$ & & & \\
\hline \multirow[t]{4}{*}{ Vegetable group* } & $0-5$ & 5 & $>100 \%$ recommendations & $55 \cdot 3$ \\
\hline & & 3 & $50-100 \%$ recommendations & $27 \cdot 3$ \\
\hline & & 1 & $<50 \%$ recommendations & $17 \cdot 4$ \\
\hline & & 0 & $0 \%$ recommendations & 0.0 \\
\hline \multirow[t]{4}{*}{ Fruit group* } & $0-5$ & 5 & $>100 \%$ recommendations & 48.8 \\
\hline & & 3 & $50-100 \%$ recommendations & $27 \cdot 8$ \\
\hline & & 1 & $<50 \%$ recommendations & $22 \cdot 2$ \\
\hline & & 0 & $0 \%$ recommendations & $1 \cdot 2$ \\
\hline \multirow{4}{*}{ Grain group* } & $0-5$ & 5 & $>100 \%$ recommendations & 3.9 \\
\hline & & 3 & $50-100 \%$ recommendations & 40.5 \\
\hline & & 1 & $<50 \%$ recommendations & $55 \cdot 0$ \\
\hline & & 0 & $0 \%$ recommendations & 0.6 \\
\hline \multirow[t]{4}{*}{ Fibre $^{*}$} & $0-5$ & 5 & $>100 \%$ recommendations & 1.1 \\
\hline & & 3 & $50-100 \%$ recommendations & 44.7 \\
\hline & & 1 & $<50 \%$ recommendations & 53.8 \\
\hline & & 0 & $0 \%$ recommendations & 0.4 \\
\hline \multirow[t]{4}{*}{ Protein } & $0-5$ & 5 & $>100 \%$ recommendations & 95.4 \\
\hline & & 3 & $50-100 \%$ recommendations & 4.6 \\
\hline & & 1 & $<50 \%$ recommendations & 0.0 \\
\hline & & 0 & $0 \%$ recommendations & 0.0 \\
\hline \multirow[t]{4}{*}{ Iront } & $0-5$ & 5 & $>100 \%$ recommendations & 30.4 \\
\hline & & 3 & $50-100 \%$ recommendations & 55.6 \\
\hline & & 1 & $<50 \%$ recommendations & 14.0 \\
\hline & & 0 & $0 \%$ recommendations & 0.0 \\
\hline Calcium $†$ & $0-5$ & 5 & $>100 \%$ recommendations & $25 \cdot 3$ \\
\hline & & 3 & $50-100 \%$ recommendations & $53 \cdot 1$ \\
\hline & & 1 & $<50 \%$ recommendations & 21.5 \\
\hline & & 0 & $0 \%$ recommendations & 0.0 \\
\hline Vitamin C† & $0-5$ & 5 & $>100 \%$ recommendations & $50 \cdot 1$ \\
\hline & & 3 & $50-100 \%$ recommendations & $26 \cdot 1$ \\
\hline & & 1 & $<50 \%$ recommendations & $23 \cdot 6$ \\
\hline & & 0 & $0 \%$ recommendations & 0.1 \\
\hline Moderation & $0-30$ & & & \\
\hline Total fat & $0-6$ & 6 & $\leq 30 \%$ of total energy $/ \mathrm{d}$ & $5 \cdot 0$ \\
\hline & & 3 & $>30-35 \%$ of total energy/d & 9.7 \\
\hline & & 0 & $>35 \%$ of total energy/d & $85 \cdot 2$ \\
\hline Saturated fat & $0-6$ & 6 & $\leq 7 \%$ of total energy/d & 4.1 \\
\hline & & 3 & $>7-10 \%$ of total energy/d & $16 \cdot 5$ \\
\hline & & 0 & $>10 \%$ of total energy/d & $79 \cdot 4$ \\
\hline Cholesterol & $0-6$ & 6 & $\leq 300 \mathrm{mg} / \mathrm{d}$ & 48.8 \\
\hline & & 3 & $>300-400 \mathrm{mg} / \mathrm{d}$ & $15 \cdot 7$ \\
\hline & & 0 & $>400 \mathrm{mg} / \mathrm{d}$ & 35.5 \\
\hline Sodium & $0-6$ & 6 & $\leq 2400 \mathrm{mg} / \mathrm{d}$ & 59.6 \\
\hline & & 3 & $>2400-3400 \mathrm{mg} / \mathrm{d}$ & $25 \cdot 2$ \\
\hline & & 0 & $>3400 \mathrm{mg} / \mathrm{d}$ & $15 \cdot 2$ \\
\hline 'Empty calorie food' & $0-6$ & 6 & $<5$ times/week & 4.7 \\
\hline & & 3 & $>5-10$ times/week & $18 \cdot 2$ \\
\hline & & 0 & $>10$ times/week & $77 \cdot 1$ \\
\hline Overall balance & $0-10$ & & & \\
\hline Macronutrient ratio (carbohydrate:protein:fat) & $0-6$ & 6 & $55-65: 10-15: 15-30$ & 2.6 \\
\hline & & 4 & $65-68: 9-16: 13-32$ & 3.1 \\
\hline & & 2 & $50-70: 8-17: 12-35$ & 5.5 \\
\hline & & 0 & Otherwise & 88.8 \\
\hline Fatty acid ratio (PUFA + MUFA/SFA) & $0-4$ & 4 & $>2$ & $20 \cdot 1$ \\
\hline & & 2 & $1 \cdot 7-2$ & $22 \cdot 3$ \\
\hline & & 0 & $<1.7$ & $57 \cdot 6$ \\
\hline
\end{tabular}

*Based on $7118 \mathrm{~kJ}(1700 \mathrm{kcal}) / 9211 \mathrm{~kJ}(2200 \mathrm{kcal}) / 11304 \mathrm{~kJ}(2700 \mathrm{kcal})$.

†Based on the recommended daily intakes for Spanish people ${ }^{37}$. 
chewing gum, snacks, soda pop and alcoholic drinks. The scoring of empty-calorie foods was also modified, assigning a score of 6 for consumption $<5$ times per week, 3 points for 5-10 times per week, and 0 points for consumption $>10$ times per week (Table 2).

Overall balance. This category examines the overall balance of diet in terms of proportions of energy sources and fatty acid composition. Detailed cut-off values and corresponding scores as proposed by Tur et al. ${ }^{26}$ are described in Table 2.

\section{Socio-demographic variables}

Qualitative variables. Sex (male/female) and physical activity (active/sedentary) were considered as dichotomous variables. Physical activity was assessed from the following dichotomous variable in the questionnaire ${ }^{35}$ : 'Practice sports about 2 days per week (yes/no)'. The following qualitative socio-demographic variables were also studied: who they live with (domestic situation), educational level of parents, work schedule of parents, who cooks, where they normally eat, time devoted to breakfast, lunch and evening meal, and the importance they assign to breakfast.

Quantitative variables. Age was categorized according to the Schofield classification for estimation of the $\mathrm{BMR}^{39}$. BMI was calculated from weight and height measurements, and obesity grade was based on the classification of Cole and co-workers ${ }^{40,41}$ and Kuczmarski et al. ${ }^{42,43}$. The results were tested by using the Harris-Bennedict formula to calculate $\%$ fat values, finding a correlation between BMI and \%fat of $R \quad 0.735(P<0 \cdot 0001)^{35}$. Cut-off points for normal BMI values in study populations were based on the mean $\pm 2 \mathrm{SD}$ ( $Z$ value). The significance level was $95 \%$. Subjects were classified as underweight (4\%), normal weight $(73.3 \%)$ or overweight $(22.7 \%)$.

\section{Statistical analysis}

Analyses were performed with SPSS version 12.0 (SPSS Inc., Chicago, IL, USA). Scores of the modified DQI-I and its four main categories were expressed as the mean and standard deviation score obtained for each component of the DQI-I, and the percentage of the population for each component subcategory was calculated. Student's $t$ test, one-way ANOVA, and univariate and multivariate linear regression analyses were used to study the association between modified DQI-I scores and values of socio-economic, habit and body composition variables (significance of $P \leq 0 \cdot 05$ ).

\section{Results}

The study sample comprised 288 young people, $44.1 \%$ females and $55.9 \%$ males. The sex distribution of the sample did not significantly differ from the current sex distribution in the population of southern Spain ${ }^{44}$. The mean age was 12.88 (SD 2.78) years (range 6-18 years).

The mean total modified DQI-I score was approximately $57 \%$ of the possible score $(100 \%)$. The highest score was for adequacy, followed by variety and moderation. The lowest score was for overall balance (Table 1). Regarding the adequacy, a large proportion of the population reported an intake of proteins, vitamin $\mathrm{C}$, calcium, fruit, iron and vegetables that were $50 \%$ higher than recommendations (Table 2). However, most of the young people consumed less than $50 \%$ of the recommended intake of fibre and failed to meet recommended intakes of grain groups. Regarding the variety, $70.7 \%$ daily consumed at least one serving from each food group or missed only one food group, and $72.2 \%$ daily consumed three or more different sources of protein (Table 2). In the moderation category, only 5.0 and $4.1 \%$ of the sample were within the limits set for fat and saturated fat, respectively. Cholesterol intake was $\leq 300 \mathrm{mg} / \mathrm{d}$ in $48.8 \%$ of the population and $>400 \mathrm{mg} / \mathrm{d}$ in $35.5 \%$. Around $60 \%$ met the goal for sodium intake. Only $4.7 \%$ of the population consumed empty-calorie foods less than five times a week. A very poor balance was found for energy-yielding nutrients and fatty acids.

Comparative analyses (Student's $t$ test and ANOVA) of socio-economic, habit and body composition, with the modified DQI score as dependent variable, showed a significant relationship between score and: age $(P=0.009)$, with younger children obtaining a better mean DQI score; physical activity $(P=0.036)$, with better mean score for active than sedentary individuals; domestic situation $(P=0.025)$, with best score for those living with parents and siblings; education level of mothers $(P=0 \cdot 029)$, with best scores for children of women with a university education; lunch location $(P=0.041)$, with significantly better scores for those eating at school versus other places; and breakfast $(P=0.025)$ and lunch $(P=0.049)$ duration, with better scores for those dedicating more time to these meals (Table 3). In a subsequent univariate linear regression analysis of socio-demographic variables, age $(P=0.007)$, physical activity $(P=0.036)$ and breakfast duration $(P=0.003)$ continued to show a significant relationship with DQI score. A multivariate analysis of these three variables was then performed, in pairs and in combination, in order to test for confounding factors. The duration of breakfast was again significantly associated with the DQI score $(P=0.029)$, whereas the association with physical activity was close to significance $(P=0.065)$ and there was no significant relationship with age $(P=0.084)$.

\section{Discussion}

A modified DQI-I was used to evaluate the diet quality of a representative sample of young people in southern Spain.

The mean score of the study population was $56 \cdot 31 \%$ of the full score, lower than mean DQI-I scores reported in the USA and China and higher than mean scores observed in the Balearic Islands ${ }^{26}$. According to the criteria of Kim et al. ${ }^{25}$, scores below $60 \%$ indicate a poor-quality diet, but it is arguable whether DQI-I criteria for high-quality diets are wholly applicable to Mediterranean-type diets.

The highest scores in the present group were for adequacy and variety, as also found in the Balearic population ${ }^{22}$. However, the DQI-I assumes that a diet including various protein sources is also a feature of a good varied diet, which may be questionable in cultures where animal foods are routinely consumed. Moreover, southern Spain is undergoing a change in dietary patterns and therefore in traditional protein sources, which may increase the score for their diet in this aspect of variety. Therefore, it may be more appropriate in this setting to select another food group for this measure of variability, such as vegetables, fruit or grain. 
Table 3. Association between Diet Quality Index (DQI-I) and socio-demographic variables

\begin{tabular}{|c|c|c|c|c|c|c|c|c|}
\hline & & \multicolumn{2}{|c|}{ DQI } & \multicolumn{2}{|c|}{$t$ test/ANOVA ${ }^{*}$} & \multicolumn{3}{|c|}{ Univariate linear regression† } \\
\hline & & Mean & SD & $F$ & $P$ & $\beta$ & $(\operatorname{SEM} \beta)$ & $P$ \\
\hline \multirow[t]{2}{*}{ Sex } & Male & $56 \cdot 1$ & $9 \cdot 0$ & -0.354 & 0.724 & 0.443 & $1 \cdot 25$ & 0.724 \\
\hline & Female & $56 \cdot 5$ & $10 \cdot 0$ & & & & & \\
\hline \multirow[t]{3}{*}{ Age } & $6-9$ years & $60 \cdot 8$ & $9 \cdot 0$ & 4.756 & 0.009 & -4.090 & 1.50 & 0.007 \\
\hline & $10-17$ years & 55.5 & 9.4 & & & & & \\
\hline & 18 years & $56 \cdot 1$ & $8 \cdot 0$ & & & & & \\
\hline \multirow[t]{4}{*}{ BMI $\left(\mathrm{kg} / \mathrm{m}^{2}\right)$} & $<17 \cdot 63$ & $55 \cdot 2$ & $8 \cdot 7$ & 0.503 & 0.681 & 0.043 & 0.56 & 0.939 \\
\hline & $17 \cdot 63-19.90$ & $57 \cdot 3$ & $9 \cdot 8$ & & & & & \\
\hline & $19 \cdot 90-22 \cdot 67$ & $56 \cdot 3$ & $8 \cdot 9$ & & & & & \\
\hline & $>22 \cdot 67$ & 55.7 & 9.9 & & & & & \\
\hline \multirow[t]{2}{*}{ Physical activity level } & Active & $57 \cdot 1$ & $9 \cdot 6$ & $2 \cdot 104$ & 0.036 & -2.883 & 1.37 & 0.036 \\
\hline & Sedentary & $54 \cdot 2$ & 8.6 & & & & & \\
\hline \multirow{3}{*}{ Obesity level } & Underweight & $56 \cdot 5$ & 7.9 & $0 \cdot 310$ & 0.733 & 0.854 & 1.33 & 0.524 \\
\hline & Normal weight & $55 \cdot 9$ & $9 \cdot 3$ & & & & & \\
\hline & Overweight & $57 \cdot 1$ & $9 \cdot 3$ & & & & & \\
\hline \multirow[t]{7}{*}{ Living at home with } & Parents and siblings & $56 \cdot 3$ & $9 \cdot 2$ & 2.458 & 0.025 & -0.046 & 0.39 & 0.907 \\
\hline & Father and mother & $55 \cdot 7$ & $9 \cdot 1$ & & & & & \\
\hline & Mother & 57.8 & $12 \cdot 7$ & & & & & \\
\hline & Mother and siblings & $53 \cdot 3$ & $6 \cdot 8$ & & & & & \\
\hline & Father & $78 \cdot 0$ & $6 \cdot 2$ & & & & & \\
\hline & Father and siblings & $67 \cdot 7$ & $8 \cdot 6$ & & & & & \\
\hline & Other & $52 \cdot 6$ & $10 \cdot 4$ & & & & & \\
\hline \multirow[t]{3}{*}{ Education level of father } & Low & $56 \cdot 5$ & 11.4 & 0.735 & 0.480 & 0.580 & 0.87 & 0.506 \\
\hline & Medium & $55 \cdot 6$ & 8.5 & & & & & \\
\hline & High & $57 \cdot 3$ & $9 \cdot 2$ & & & & & \\
\hline \multirow[t]{3}{*}{ Educational level of mother } & Low & $56 \cdot 9$ & $11 \cdot 1$ & $3 \cdot 612$ & 0.029 & 1.111 & 0.86 & 0.199 \\
\hline & Medium & 54.5 & 8.5 & & & & & \\
\hline & High & $58 \cdot 2$ & $9 \cdot 3$ & & & & & \\
\hline \multirow[t]{3}{*}{ Location of lunch } & Home & 55.9 & 9.4 & 3.252 & 0.041 & $1 \cdot 120$ & 1.35 & 0.408 \\
\hline & School & $59 \cdot 3$ & $9 \cdot 6$ & & & & & \\
\hline & Other & $50 \cdot 2$ & $2 \cdot 7$ & & & & & \\
\hline \multirow[t]{3}{*}{ Time spent on breakfast } & $<10 \min$ & 55.4 & $9 \cdot 2$ & $3 \cdot 162$ & 0.025 & 3.062 & 1.03 & 0.003 \\
\hline & $10-20 \mathrm{~min}$ & $58 \cdot 1$ & $10 \cdot 0$ & & & & & \\
\hline & $>20 \min$ & $60 \cdot 4$ & 4.9 & & & & & \\
\hline \multirow{4}{*}{ Time spent on lunch } & $<15 \min$ & 53.4 & $9 \cdot 8$ & $2 \cdot 419$ & 0.049 & $1 \cdot 161$ & 1.03 & 0.263 \\
\hline & $15-30 \mathrm{~min}$ & $55 \cdot 7$ & $9 \cdot 6$ & & & & & \\
\hline & $30-60 \mathrm{~min}$ & $57 \cdot 2$ & $8 \cdot 8$ & & & & & \\
\hline & $>60 \min$ & $69 \cdot 0$ & 9.4 & & & & & \\
\hline \multirow[t]{3}{*}{ Time spent on dinner } & $<15 \min$ & 54.4 & $8 \cdot 8$ & 1.692 & 0.169 & 0.000 & 1.05 & 1.000 \\
\hline & $15-30 \mathrm{~min}$ & $56 \cdot 6$ & 9.8 & & & & & \\
\hline & $>30 \min$ & $55 \cdot 7$ & $8 \cdot 7$ & & & & & \\
\hline \multirow[t]{3}{*}{ Activity during lunch? } & No distractions & 57.9 & $9 \cdot 3$ & 0.719 & 0.488 & $-0 \cdot 104$ & 0.92 & 0.910 \\
\hline & Distractions & $55 \cdot 3$ & $10 \cdot 6$ & & & & & \\
\hline & Talking & $56 \cdot 5$ & 8.9 & & & & & \\
\hline \multirow[t]{3}{*}{ Breakfast considered important } & Yes & $59 \cdot 8$ & $12 \cdot 6$ & 1.845 & 0.160 & -4.697 & $2 \cdot 51$ & 0.063 \\
\hline & No & $56 \cdot 1$ & $9 \cdot 2$ & & & & & \\
\hline & Don't know & $50 \cdot 1$ & $9 \cdot 0$ & & & & & \\
\hline
\end{tabular}

*Comparison of mean DQI scores among groups by ANOVA for polychotomous and Student's $t$ test for dichotomous variables.

† Univariate linear regression analysis considering effect of single socio-demographic (independent) variable on DQI score (dependent variable).

Adequacy reflects compliance with prevailing recommendations to ensure a healthy diet. The diet of the present population was assigned a high score in this category for intake of protein, iron and calcium but a low score for intake of fruit, vegetables, grain and fibre.

According to scores obtained with this DQI-I, the Spanish diet lacks moderation and is highly unbalanced. Very poor scores were obtained for moderation in total fat and saturated fat consumption. The DQI-I sets strict standards, especially for fat intake, in line with US recommendations. However, although total fat intake in Mediterranean countries is similar to that in Northern Europe and North America, at around $38-40 \%{ }^{19-22}$, the incidence of CVD and diet-related cancer is lower ${ }^{29,45}$. Importantly, olive oil is a central element of
Mediterranean-type diets and makes a key contribution to its healthy properties. Moreover, studies in the Mediterranean area have demonstrated that the intake of vegetables is augmented by the consumption of olive oil ${ }^{46,47}$. Nevertheless, the large amounts of olive oil traditionally consumed by Mediterranean populations worsen their diet index score because it is considered an immoderate intake of fat. It appears reasonable to suggest that dietary evaluations and guidelines should take account of the quality rather than the quantity of fat, aimed at reducing intake of saturated fat but not of olive oil $^{8,9}$. The DQI-I establishes moderate fat consumption as $<30 \%$ of total energy, lower than the percentage found in the Spanish diet. In fact, only $5 \%$ of the young Spanish population in the present study had a fat intake below $30 \%$ of 
energy intake, even lower than the $14.5 \%$ of the population in the Balearic Islands (14.5\%).

The original DQI-I categorizes olive oil and wine as empty-calorie foods with low nutrient density, but this is not appropriate to the Mediterranean diet. Olive oil contains a high proportion of MUFA, vitamin $\mathrm{E}$ and numerous antioxidant phenolic compounds ${ }^{48-50}$. Besides alcohol, wine also supplies antioxidant phenolic compounds ${ }^{51-54}$. Therefore, in the present adaptation of the DQI-I, these items of high energetic value were only classified as empty-calorie foods when their use was only occasional and moderate, as recommended in the food pyramid for the Spanish population ${ }^{38}$. Further research is warranted to establish the most appropriate criteria for moderation in the diet of Mediterranean populations.

The diet of the study population also obtained a very low score for its overall balance, i.e. the proportionality in energy sources and fatty acid composition. However, the macronutrient ratios used to evaluate energy sources require that the percentage of energy from fat be $\leq 30 \%$ and, as explained earlier, very few individuals met this goal. In the present sample, the mean ratio of PUFA and MUFA to SFA was 1.08 , similar to findings in the other Mediterranean population in the Balearic Islands ${ }^{26}$. The higher consumption of olive oil, the usual source of unsaturated fat in the Mediterranean setting, leads to a much higher intake of MUFA than PUFA. In fact, current Spanish Nutritional Objectives recommend $20 \%$ of total energy from MUFA and $5 \%$ from PUFA $^{8,9}$. Further research is required to establish whether our adaptation of the DQI-I provides an accurate evaluation of the diet of young people in southern Spain or whether further adjustments are required.

The use of a single diet quality score for international comparisons is problematic. For dietary recommendations to be relevant and suitable for a given population, they should take account of prevailing food patterns in that population $^{8,9,14,15,26,29,55,56}$

The present results suggest that age, physical activity, domestic situation, mother's educational level, the place where lunch is usually eaten, and the time taken to eat breakfast and lunch may be factors with an influence on the optimal $\operatorname{diet}^{57}$. In the multivariate analysis, physical activity level and breakfast duration emerged as independent factors. Sedentary young people not only consumed less energy but had a worse diet compared with active youngsters, and this combination clearly increases the risk of obesity and related diseases $^{58}$. Interestingly, older children dedicated less time to breakfast, suggesting that age may be a confounding factor and that it is the time devoted to taking breakfast that has a positive effect on diet quality ${ }^{14,15,57}$. Children should be taught the value of breakfast at an early age in order to improve their diet in later years.

\section{Acknowledgements}

This work was supported by grants from the Spanish Ministry of Education and Science (FPU programme). The authors thank Richard Davies for his assistance with the English version.

\section{References}

1. Aranceta J \& Serra-Majem L (2001) Working Party for the Development of Food-based Dietary Guidelines for the Spanish Population: dietary guidelines for the Spanish population. Public Health Nutr 4, 1403-1408.

2. Gonzalez CA, Argilaga S, Agudo A, et al. (2002) (Sociodemographic differences in adherence to the Mediterranean dietary pattern in Spanish populations). Gac Sanit 16, 214-221.

3. Trichopoulou A \& Vasilopoulou E (2000) Mediterranean diet and longevity. Br J Nutr 84, Suppl. 2, S205-S209.

4. Trichopoulou A (2001) Mediterranean diet: the past and the present. Nutr Metab Cardiovasc Dis 11, Suppl. 4, S1-S4.

5. Trichopoulou A, Costacou T, Bamia C \& Trichopoulos D (2003) Adherence to a Mediterranean diet and survival in a Greek population. $N$ Engl J Med 348, 2595-2596.

6. deKoning L \& Anand SS (2004) Vasc Med 9, 145-146.

7. Trichopoulou A, Bamia C \& Trichopoulos D (2005) Mediterranean diet and survival among patients with coronary heart disease in Greece. Arch Intern Med 25, 929-935.

8. Serra-Majem L \& Aranceta J (2001) Nutritional objectives for the Spanish population. Consensus from the Spanish Society of Community Nutrition. Public Health Nutr 4, 1409-1413.

9. Serra-Majem L (2001) Más beneficios de la dieta mediterránea? Nutr Obesidad 4, 43-46.

10. Trichopoulou A (2004) Traditional Mediterranean diet and longevity in the elderly: a review. Public Health Nutr 7, 943-947.

11. Serra-Majem L, Roman B \& Estruch R (2006) Scientific evidence of interventions using the Mediterranean diet: a systematic review. Nutr Rev 64, Suppl. 2 Pt 2, S27-S47.

12. Hu FB (2003) The Mediterranean diet and mortality - olive oil and beyond. N Engl J Med 348, 2595-2596.

13. Elmadfa I \& Freisling H (2005) Fat intake, diet variety and health promotion. Forum Nutr 57, 1-10.

14. Aranceta J, Serra-Majem L, Ribas L \& Perez-Rodrigo C (2001) Breakfast consumption in Spanish children and young people. Public Health Nutr 4, 1439-1444.

15. Aranceta J (2001) Spanish food patterns. Public Health Nutr 4, $1399-1402$.

16. Moreno LA, Sarría A \& Popkin BM (2002) The nutrition transition in Spain: a European Mediterranean country. Eur J Clin Nutr 56, 992-1003.

17. Serra-Majem L, Ribas L, Lloveras G \& Salleras L (1993) Changing patterns of fat consumption in Spain. Eur $J$ Clin Nutr 47, Suppl. 1, S13-S20.

18. Martinez-Gonzalez MA \& Estruch R (2004) Mediterranean diet, antioxidants and cancer: the need for randomized trials. Eur $J$ Cancer Prev 13, 327-335.

19. Trichopoulou A, Orfanos P, Norat T, et al. (2004) (Changes on nutrient and food intakes in Mallorca throughout the XXth century). Rev Esp Nutr Comun 10, 6-16.

20. Tur JA, Romaguera D \& Pons A (2004) Adherence to the Mediterranean dietary pattern among the Balearic Islands population. Br J Nutr 92, 341-346.

21. Tur JA, Romaguera D \& Pons A (2004) Food consumption patterns in a Mediterranean region: is the Mediterranean diet still present? Ann Nutr Metab 48, 193-201.

22. Tur JA, Serra-Majem L, Romaguera D \& Pons A (2005) Does the diet of the Balearic population, a Mediterranean type diet, still provide adequate antioxidant nutrient intakes? Eur $J$ Nutr 44, 204-213.

23. Lambert J, Agostoni C, Elmadfa I, Hulshof K, Krause E, Livingstone B, Socha P, Pannemans D \& Samartin S (2004) Dietary intake and nutritional status of children and adolescents in Europe. Br J Nutr 92, Suppl. 2, S147-S211. 
24. Janssen I, Katzmarzyk PT, Boyce WF, Vereecken C, Mulvihill C, Roberts C, Currie C \& Pickett W (2005) Health Behaviour in School-Aged Children Obesity Working Group. Comparison of overweight and obesity prevalence in school-aged youth from 34 countries and their relationships with physical activity and dietary patterns. Obes Rev 6, 123-132.

25. Kim S, Haines PS, Siega-Riz AM \& Popkin BM (2003) The Diet Quality Index-International (DQI-I) provides and effective tool for cross-national comparison of diet quality as illustrated by China and the United States. J Nutr 133, 3476-3484.

26. Tur JA, Romaguera D \& Pons A (2005) The Diet Quality IndexInternational (DQI-I): is it a useful tool to evaluate the quality of the Mediterranean diet? Br J Nutr 93, 369-376.

27. Kant AK (1996) Indexes of overall diet quality: a review. $J$ Am Diet Assoc 96, 785-791.

28. Haines PS, Siega-Riz AM \& Popkin BM (1999) The Diet Quality Index revised: a measurement instrument for populations. J Am Diet Assoc 99, 697-704.

29. Gerber MJ, Scali JD \& Michaud A (2000) Profiles of a healthful diet and its relationship to biomarkers in a population sample from Mediterranean southern France. Am J Diet Assoc 100, $1164-1171$.

30. Marshall TA, Stumbo PJ, Warren JJ \& Xie XJ (2001) Inadequate nutrient intakes are common and are associated with low diet variety in rural, community-dwelling elderly. J Nutr 131, 2192-2196.

31. Tangney CC, Evans DA, Bienias JL \& Morris MC (2001) Healthy eating index of black and white older adults. Nutr Res 21, 1411-1423.

32. Weinstein SJ, Vogt TM \& Gerrior SA (2004) Healthy eating index scores are associated with blood nutrient concentrations in the Third National Health and Nutrition Examination Survey. Am J Diet Assoc 104, 576-584.

33. Fornes NS, Stringhini ML \& Elias BM (2003) Reproducibility and validity of a food-frequency questionnaire for use among lowincome Brazilian workers. Public Health Nutr 6, 821-827.

34. Kusama K, Le DS, Hanh TT, Takahashi K, Hung NT, Yoshiike N \& Yamamoto S (2005) Reproducibility and validity of a food frequency questionnaire among Vietnamese in Ho Chi Minh City. J Am Coll Nutr 24, 466-473.

35. Mariscal M (2006) Nutrition and Physical Activity in Spanish Children and Adolescents. Granada: University of Granada, ISBN 8433838024.

36. Jimenez Cruz A, Cervera Ral P \& Bacardí Gascón M 2001 Novartis-Dietsource version 1.2. (c)0105071807.

37. Ortega RM, López-Sobaler AM, Requejo AM \& Andrés $\mathrm{P}$ (2004) La composición de los alimentos. Herramienta básica para la valoración nutricional. Madrid: Complutense.

38. Guia de la Alimentación Soludable Sociedad Española de Nutrición Comunitaria (SENC) (2004). Madrid: Everest. ISBN 84-241-0851-5.

39. Schofield WN (1985) Predicting basal metabolic rate, new standards and review of previous work. Hum Nutr Clin Nutr 39C, Suppl.1, 5-41.

40. Cole TJ, Bellizzi MC, Flegal KM \& Dietz WH (2000) Establishing a standard definition for child overweight and obesity worldwide: international survey. $B r$ Med $J 6$ (320; 7244), 1240-1243.

41. Cole TJ \& Henry CJ (2005) The Oxford Brookes basal metabolic rate database - a reanalysis. Public Health Nutr 8, $1202-1212$.

42. Kuczmarski RJ, Ogden CL, Grummer-Strawn LM, Flegal KM, Guo SS, Wei R, Mei Z, Curtin LR, Roche AF \& Johnson CL (2000) CDC growth charts: United States. Adv Data 8 (314), $1-27$.

43. Kuczmarski RJ, Ogden CL, Guo SS, et al. (2002) 2000 CDC Growth Charts for the United States: methods and development. Vital Health Stat 246, 1-190.

44. Instituto Nacional de Estadística (2003) Censo de población y residencia 2001. Madrid: INE.

45. Serra-Majem L, Ferro-Luzzi A, Bellizzi M \& Salleras L (1997) Nutrition policies in Mediterranean Europe. Nutr Rev 55, $342-357$

46. Trichopoulos D (2002) In defence of the Mediterranean diet Eur J Clin Nutr 56, 928-929.

47. Serra-Majem L, Ngo de la Cruz J, Ribas L \& Tur JA (2003) Olive oil and the Mediterranean diet: beyond the rhetoric. Eur J Clin Nutr 57, Suppl. 1, S2-S7.

48. Owen RW, Giacosa A, Hull WE, Haubner R, Wurtele G, Spiegelhalder B \& Bartsch H (2000) Olive-oil consumption and health: the possible role of antioxidants. Lancet Oncol 1, $107-112$

49. Visioli F \& Galli C (2001) The role of antioxidants in the Mediterranean diet. Lipids 36, Suppl., S49-S52.

50. Briante R, Febbraio F \& Nucci R (2003) Antioxidant properties of low molecular weight phenols present in the Mediterranean diet. J Agric Food Chem 51, 6975-6981.

51. Bianchini F \& Vainio H (2003) Wine and resveratrol: mechanisms of cancer prevention? Eur J Cancer Prev 12, 417-425.

52. Goldfinger TM (2003) Beyond the French paradox: the impact of moderate beverage alcohol and wine consumption in the prevention of cardiovascular disease. Cardiol Clin 2 449-457.

53. Lopez-Velez M, Martinez-Martinez F \& Del Valle-Ribes C (2003) The study of phenolic compounds as natural antioxidants in wine. Crit Rev Food Sci Nutr 43, 233-244.

54. Pulido R, Hernandez-Garcia M \& Saura-Calixto F (2003) Contribution of beverages to the intake of lipophilic and hydrophilic antioxidants in the Spanish diet. Eur J Clin Nutr 57, $1275-1278$.

55. Drewnowski A, Henderson SA, Shore AB, Fischler C, Preziosi P \& Hercberg S (1996) Diet quality and dietary diversity in France: implications for the French paradox. $J$ Am Diet Assoc 96, 663-669.

56. Popkin BM, Zizza C \& Siega-Riz AM (2003) Who is leading the change? U.S. Dietary quality comparison between 19651996. Am J Prev Med 25, 1-8.

57. Aranceta J, Perez-Rodrigo C, Ribas L \& Serra-Majem L (2003) Sociodemographic and lifestyle determinants of food patterns in Spanish children and adolescents: the enKid study. Eur J Clin Nutr 57, Suppl. 1, S40-S44.

58. Someshwar J, Someshwar S \& Perkins KC (2006) The obese adolescent. Pediatr Ann 35, 180-186. 